مقايسه اثر آبيارى شيارى و قطرهاى با بِاب توأم با اعمال كم آبيارى بر شاخصهاى عملكردى

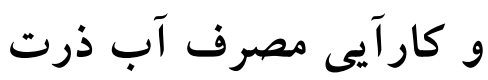

\author{
محمد عامريان، سيدابر اهيم هاشمى گرمدره"، عذرا كرمى' \\ (تاريخ دريافت:
}

جكيده

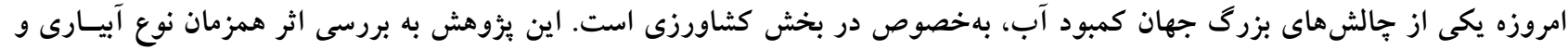

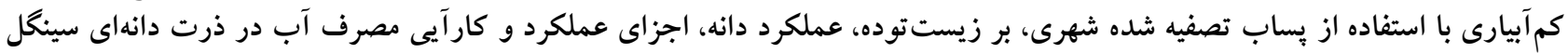

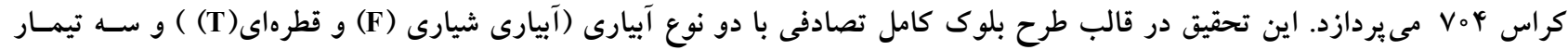

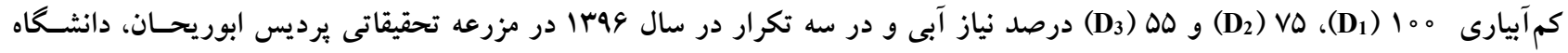

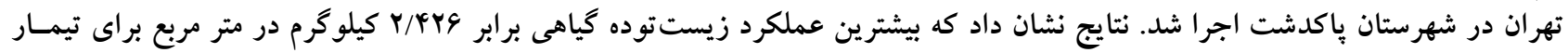

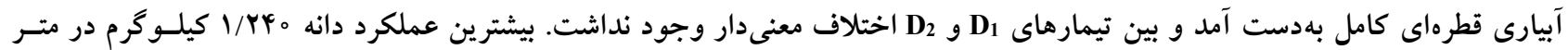

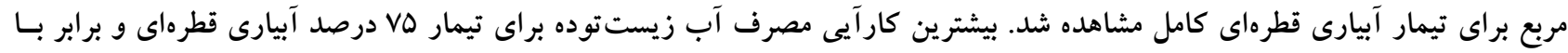

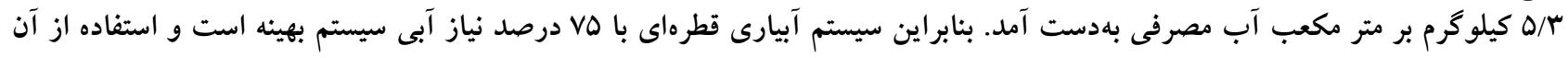

وازمهاى كليدى: آبهاى نامتعارف، روش آبيارى، عملكرد دانه، كارآيى مصرف آب 
براى آبيارى اسـتفاده شـود (N). عـالى نزاديـان و ملكسى (1) در

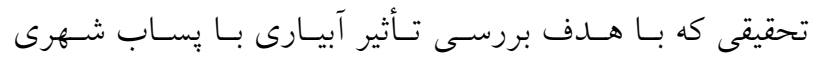

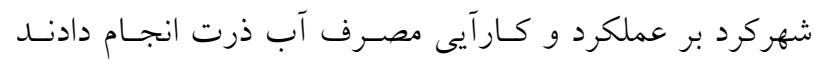

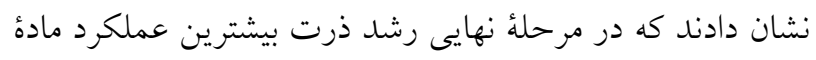

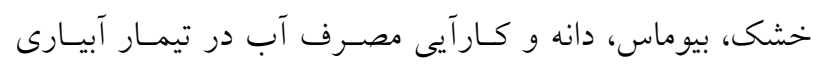

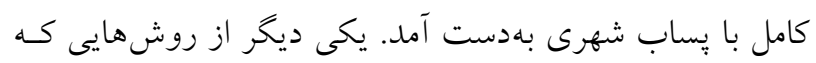

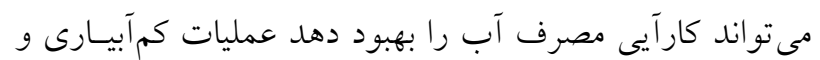

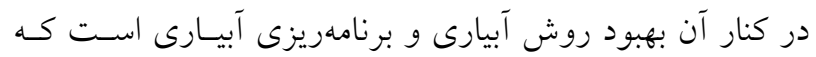

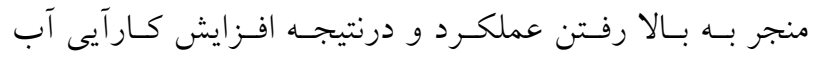
مى شود و نقش مهمى در حفظ امنيت غذايى دارد (Y). حيـدرى

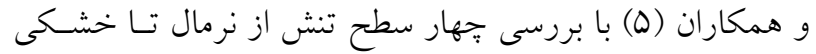

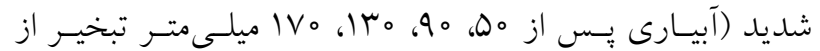

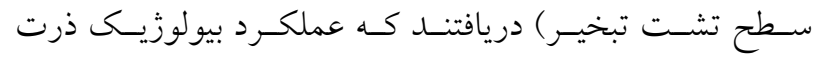
همبستخى مثبت و معنى دارى بـا عملكـــد دانسه داشـته اسـت و افزايش تنش آبى، موجب كاهش معنىدار در صفات عملكـردى

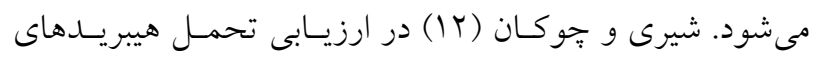

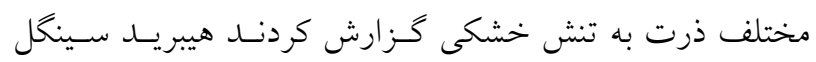

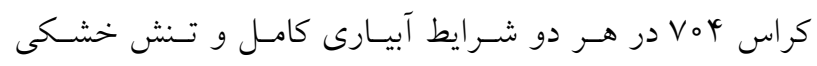

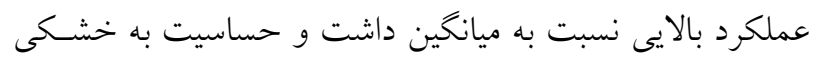

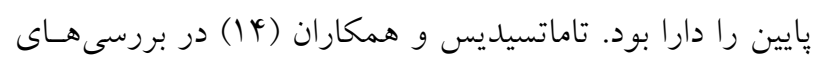

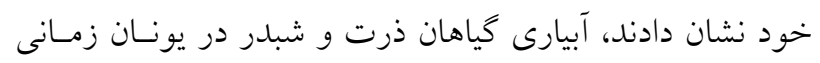

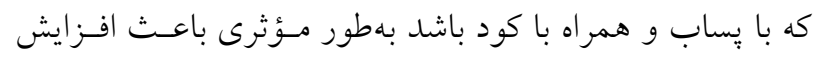

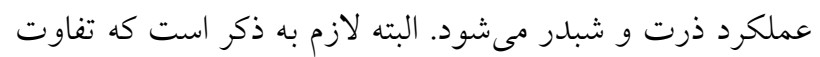

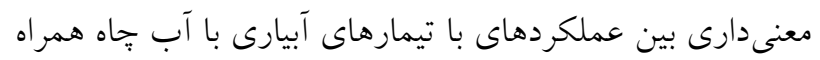

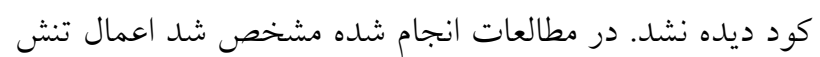

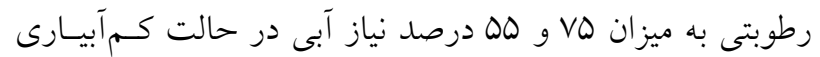

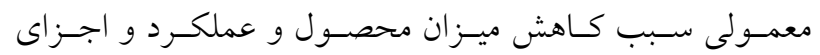
عملكرد كَياه ذرت مىشود اما اين كـاهش محصـول در حالـت

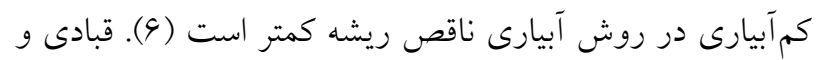

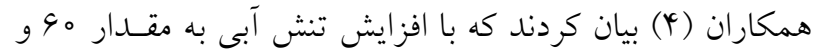

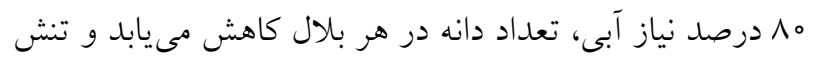
رطوبتى موجب كاهش معنى دار وزن صــ دانسه شـد، همجنـين

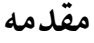

كمبود آب در بسـيارى از كشـورهاى جهـان بـهعنـوان يكسى از فاكتورهاى تأثير كذار در كشاورزى بايدار شناخته مى بــود (19).

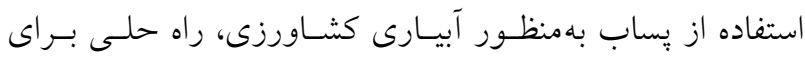

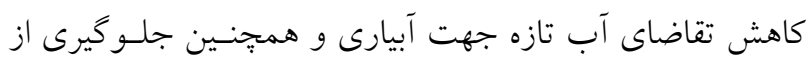

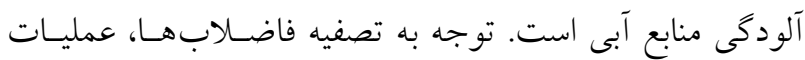

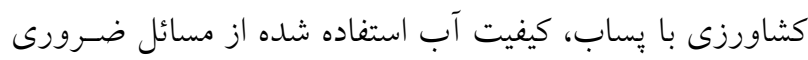

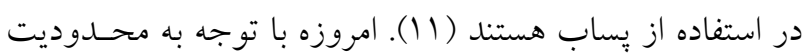

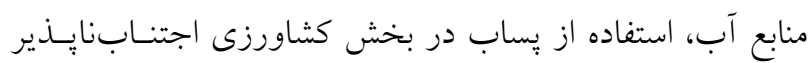

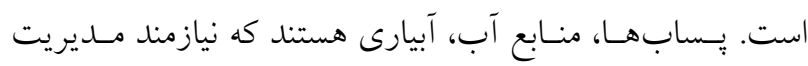

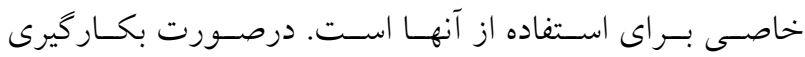

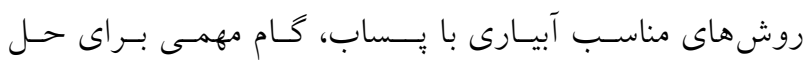

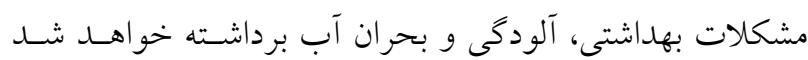

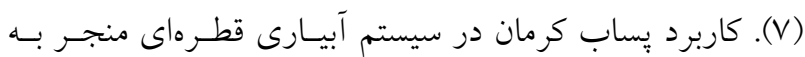

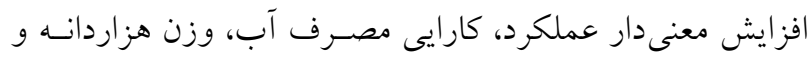
تعلداد دانه در رديف بلال نسـبت بـه سيسـتم آبيـارى شسيارى و همجِنين موجب كاهش آلودگى زيستمحيطى ناشسى از عناصـر

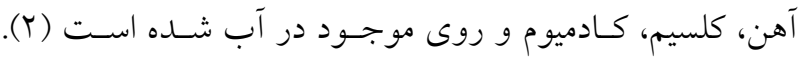

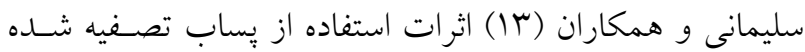
شهرى بر مهمترين شاخص هاى فيزيولوزيكى مؤثر بر رشد كَّاه

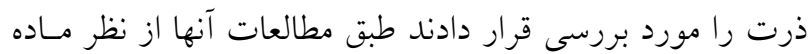

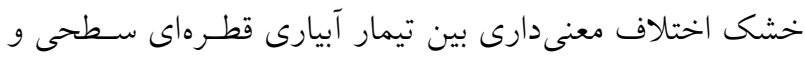

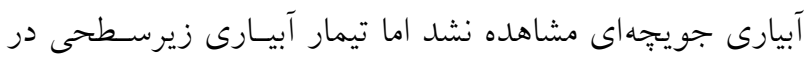

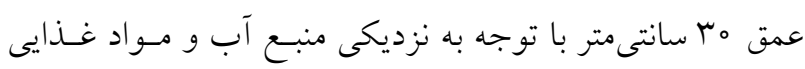

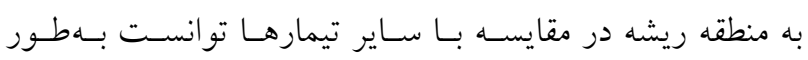

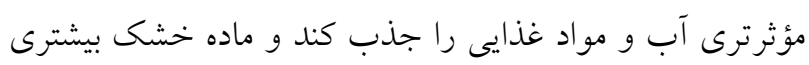

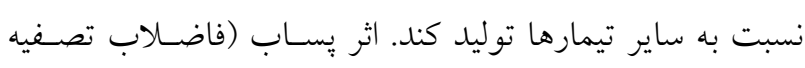

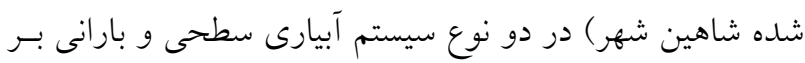

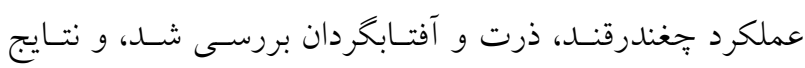

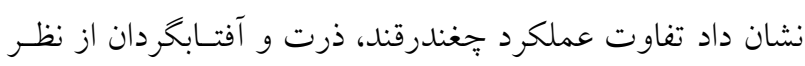
آمارى در دو سيستم آبيارى اعمال شده معنى دار نبود ولى با اين

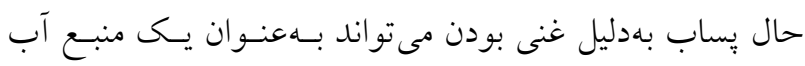


سبز شدن كياهان، در ابتدا تعداد ץ تا ץ بذر ذرت سينگل كراس

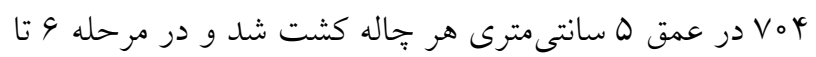

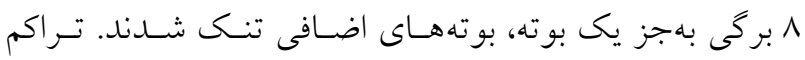

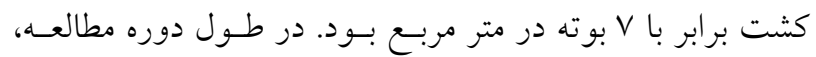

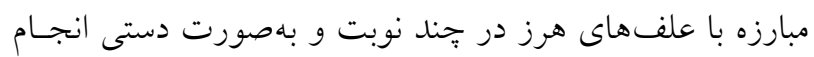

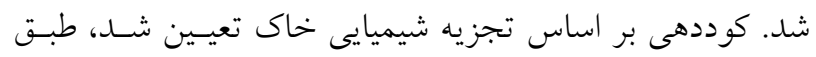

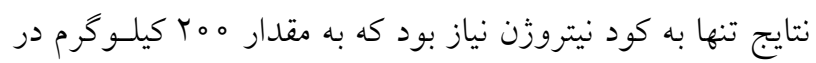

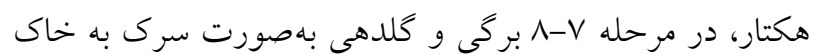

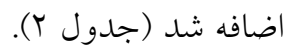
بهمدت يك ماه، تمامى كرت ها با دور آبيارى ثابت لَ با روز

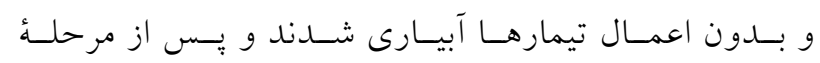

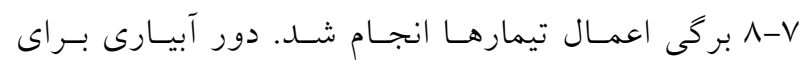

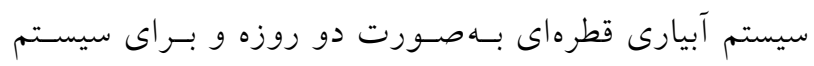
آبيارى شيارى بهصورت جهار روز يكبار درنظر كرفته شــد.

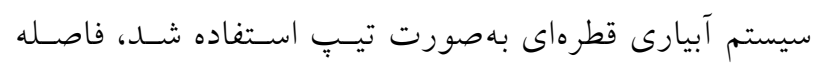

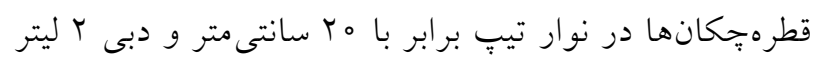

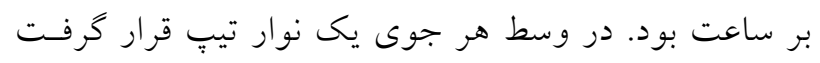

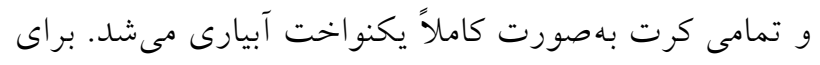

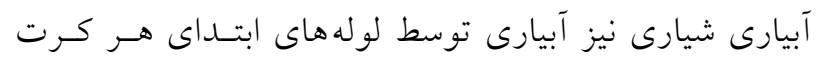

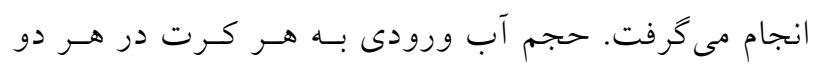

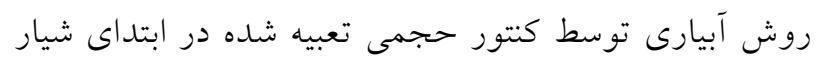

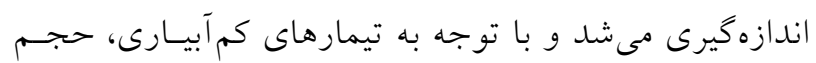

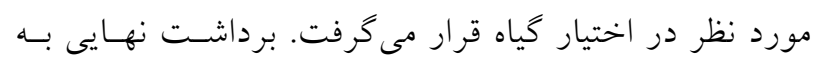
هنگام رسيدگى فيز يولوزيك دانههاى ذرت، كه با تشكيل لايه

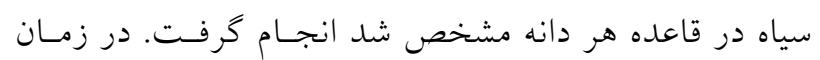

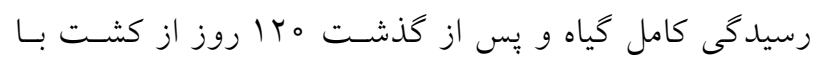

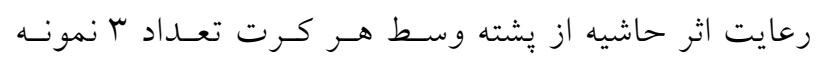

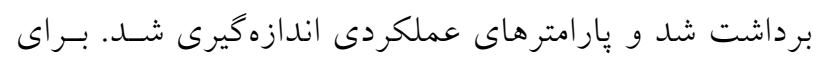

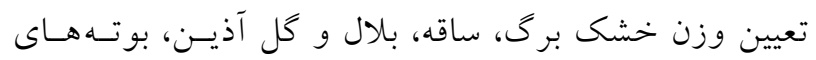

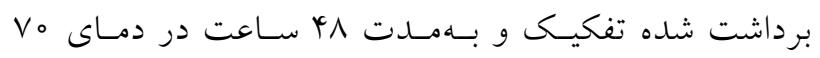

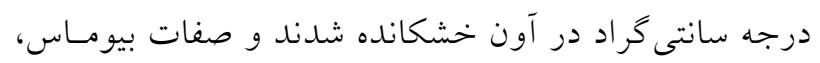

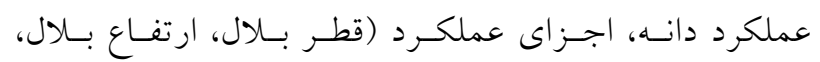

بيشترين و كمترين وزن صد دانه بـهـترتيسب مربـوط بـه سـطوح

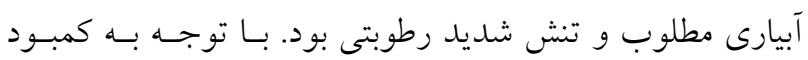

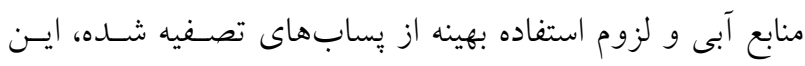

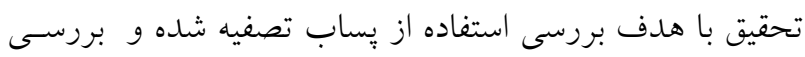

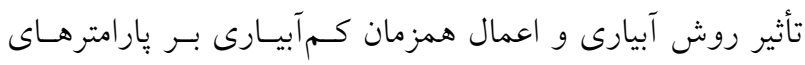

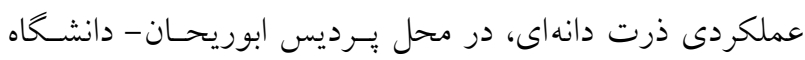

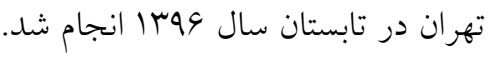

\section{مواد و روشها - (- ماد}

اين بزوهش با هدف استفاده بهينـه از منـابع آب بـهنصـوص

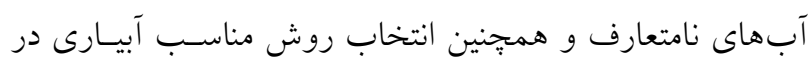

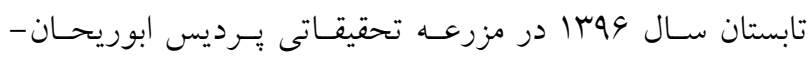

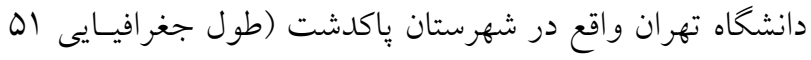

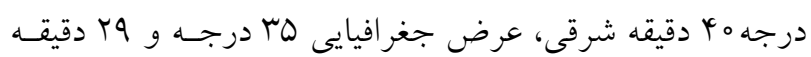

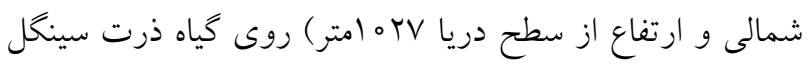

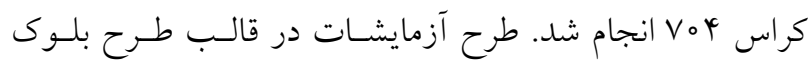

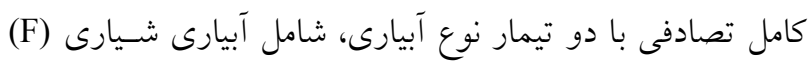

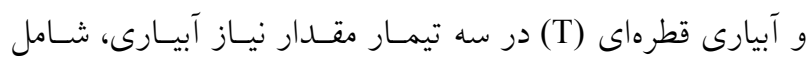

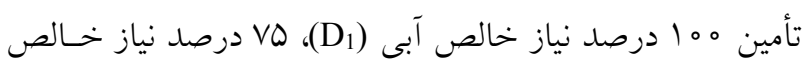

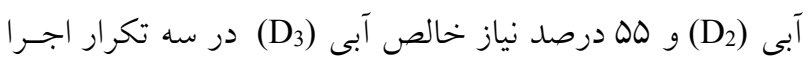

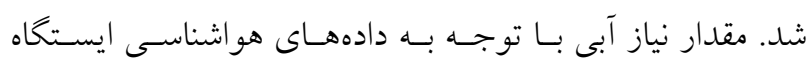

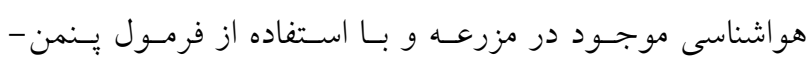

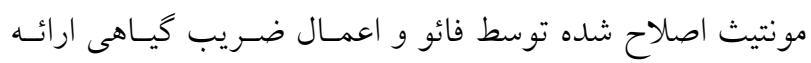

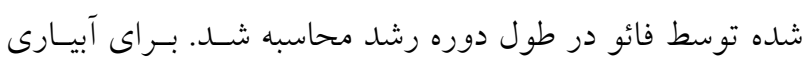
مزرعه از پِاب تصفيه شده استفاده شد. پِساب مورد استفاده در اين تحقيق از كانال بِاب تصفيه شده تصفيهخانه جنوب تهران

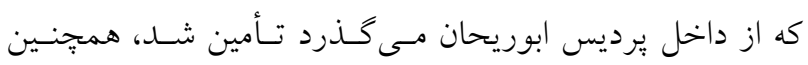

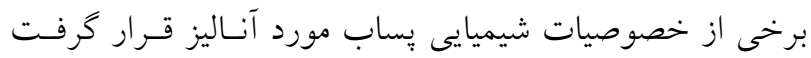

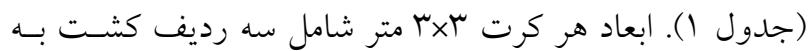
فاصله Vo سانتىمتر بود كه كياهان در هر رديـف بـا فاصـله

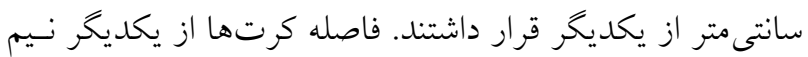
متر و فاصله بلوى يكى متر درنظر كرفته شد. بهمنظور اطمينان از 
نشريه علوم آب و خاك / سال بيست و جهارم / شماره سوم / ياييز 9هبا

جدول ا. مشخصات شيميايى بساب بههمراه حد استاندارد استفاده

\begin{tabular}{|c|c|c|}
\hline حد استاندارد استفاده در كشاورزى' & 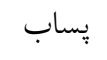 & معيار اندازهگيرى شده \\
\hline 100 & $M T / 9$ & $(\mathrm{mg} / \mathrm{L}) \mathrm{BOD}$ \\
\hline Y०o & $\Delta F / \Lambda$ & $(\mathrm{mg} / \mathrm{L}) \mathrm{COD}$ \\
\hline- & 940 & $(\mathrm{mg} / \mathrm{L}) \mathrm{TDS}$ \\
\hline$r / 9 V$ & $1 / 00$ & $(\mathrm{dS} / \mathrm{m}) \mathrm{EC}$ \\
\hline $9-\Lambda / 0$ & $V / 9$ & $\mathrm{pH}$ \\
\hline Q. & $r \Delta / v Q$ & نيتروزن نيتراتى (mg/L) \\
\hline- & $1 / \mu \wedge$ & نيتروزن نيتريتى (mg/L) \\
\hline- & $\Delta / \Lambda$ & بى كربنات (meq/L) \\
\hline 100 & $r / 9$ & كلسيم و منيزيم (meq/L) \\
\hline- & I & يتاسيم (meq/L) \\
\hline- & $191 / 21$ & سديم (meq/L) \\
\hline
\end{tabular}

1 - بركرفته از سازمان محيط زيست ايران (Q)

جدول r. مشخصات فيزيكى و شيميايى خاك مزرعه تحقيقاتى

\begin{tabular}{|c|c|c|c|c|c|c|c|c|c|c|c|}
\hline كلسيم و منيزيم & $\begin{array}{c}\text { بى كربنات } \\
\text { (meq/l) }\end{array}$ & $\begin{array}{c}\text { كربنات } \\
\text { (meq/1) }\end{array}$ & نيتروزن & $\mathrm{pH}$ & $\begin{array}{c}\mathrm{EC} \\
(\mathrm{dS} / \mathrm{m})\end{array}$ & دواد آلى & خافت & شن & سيلت & رس & عمق \\
\hline$\omega_{0}$ & $0 / 9$ & 14 & $0 / 11$ & $9 / 0$ & $1 / 4$ & $0 . / \circ \mathrm{V}$ & سيلت لوم & Tr & Q. & IV & ro-o \\
\hline$\Delta \wedge$ & $T / 9$ & $\circ$ & $\circ / 14$ & $9 / 0$ & 1 & $\circ / Y \Lambda$ & سيلت لوم & M & Q. & IV & $\varphi_{0} \circ-r_{0}$ \\
\hline TI/9 & $1 / 1$ & $\circ$ & $0 / 1 Y$ & $9 / 0$ & $1 / \mu$ & $0 / 19$ & لوم & pr & HY & 10 & $9 \circ-Y_{0}$ \\
\hline
\end{tabular}

وزن كل بلال) و ارتفاع بوته اندازهيرى شد. با توجه بـه حجـم شماره 9.2 انجام شد.

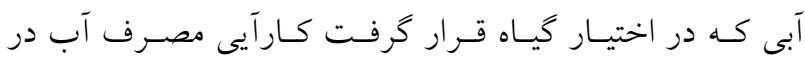
تيمارهاى مختلف نيز محاسبه شد. براى محاسبه كار آيى مصرف

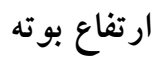
آب از رابطه (1) استفاده شد: IWUE = $\frac{Y}{I}$

مطابق نتايج بهدست آمده، تأثير نوع سيستم آبيارى روى ارتفـاع

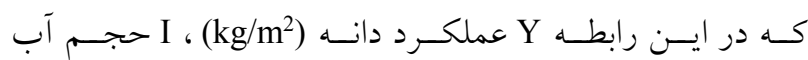
بوته در سطح بينج درصد معنى دار بوده است ولى تـأثير سطوح

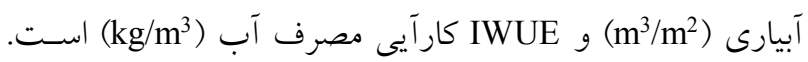

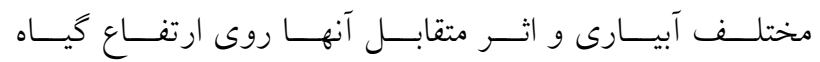
تمـامى آناليزهـا در ايسن مطالعـه توسـط نـرمافـزار SAS ورزن 
جدول r. تجزيه واريانس دادههاى مربوط به تيمارهاى نوع آب و كمآييارى بر شاخصهاى عملكرد و كارآيى مصرف آب ذرت

\begin{tabular}{|c|c|c|c|c|c|c|c|c|}
\hline كارآيى مصرف آب & $\begin{array}{c}\text { طول بلال } \\
\text { (cm) }\end{array}$ & $\begin{array}{c}\text { عملكرد دانه } \\
\left(\mathrm{gr} \mathrm{m}^{-2}\right)\end{array}$ & $\begin{array}{c}\text { قطر بلال } \\
\text { (cm) }\end{array}$ & $\begin{array}{l}\text { وزن بالال } \\
\left(\mathrm{gr} \mathrm{m}^{-2}\right)\end{array}$ & $\begin{array}{c}\text { بيو ماس } \\
\left(\mathrm{gr} \mathrm{m}^{-2}\right)\end{array}$ & $\begin{array}{l}\text { ارتفاع } \\
\text { (cm) }\end{array}$ & آزادى درجه & منابع تغييرات \\
\hline $0 . / 10 \mathrm{~ns}$ & $1 / \Delta Y^{n s}$ & $49 \wedge r / \circ \wedge$ ns & $\circ / 1 \Lambda^{n s}$ & $Y Y Q \circ N / Y Y$ ns & $G \circ \psi r V \circ /\left.\Lambda\right|^{n s}$ & $14 / 99 \mathrm{~ns}$ & r & تكرار \\
\hline I/ My ns & $\circ / \mathrm{V}^{\mathrm{ns}}$ & 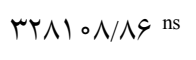 & $1 / I V^{*}$ & 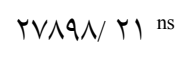 & FVYTOY/qQns & $M \Lambda^{*}$ & 1 & روش آبيارى \\
\hline $1 / \circ 0$ & $V / N Y$ & WVQSI/DG & $\circ / \circ \Delta \Delta$ & QSTGV/TD & $T_{T \Lambda} \circ V Y / Q \Lambda$ & MT/99 & r & خطا \\
\hline & 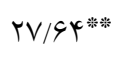 & 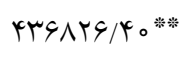 & $\circ / 9 \circ \mathrm{ns}$ & VYAMYN/Q৭*** & 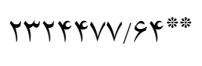 & ro94/99 ns & r & كم آبيارى \\
\hline$r / \Lambda^{*}$ & $\mid r / 9 \mu^{\mu *}$ & TYGl०G/VK" & $\circ / 1 \circ \mathrm{ns}$ & $199 \mathrm{VV} / 0 / 0 \circ \mathrm{ns}$ & $\wedge r \wedge q \leftrightarrow q / \mathrm{No*}^{*}$ & $\mu \circ \wedge / \& \& \mathrm{~ns}$ & r & كمآبيارى× \\
\hline$\mu / \varphi_{0}$ & $\mid 0 / \uparrow \Lambda$ & TVIYAV/GV & l/Ar & $\varphi \circ \wedge r G \Delta / \Delta V$ & $1 r \circ \Delta K \& q / q \mu$ & $099 / \circ \wedge$ & $\wedge$ & خطاى كل \\
\hline
\end{tabular}

جدول f. مقايسه ميانخين صفات تيمارهاى مختلف نوع آبيارى و سطوح مختلف آبيارى

\begin{tabular}{|c|c|c|c|c|c|c|c|}
\hline كارآيى مصرف آب & $\begin{array}{c}\text { طول بلال } \\
\text { (cm) }\end{array}$ & $\begin{array}{c}\text { عملكرد دانه } \\
\left(\mathrm{gr} \mathrm{m}^{-2}\right)\end{array}$ & $\begin{array}{c}\text { قطر بلال } \\
\text { (cm) }\end{array}$ & $\begin{array}{l}\text { وزن بلال } \\
\left(\mathrm{gr} \mathrm{m}^{-2}\right)\end{array}$ & $\begin{array}{l}\text { بيو ماس } \\
\left(\mathrm{gr} \mathrm{m}^{-2}\right)\end{array}$ & $\begin{array}{l}\text { ارتفاع } \\
\text { (cm) }\end{array}$ & تيمار \\
\hline$r / v q^{a}$ & $r \circ / \Lambda Y^{a}$ & $9 \mathrm{~V} \circ / \mathrm{V}^{\mathrm{a}}$ & $4 /\left.9\right|^{b}$ & $1+49 / \mathbb{A}^{\mathrm{a}}$ & $r) \circ r / q^{a}$ & $|y|\rangle^{a}$ & $\mathrm{~F}$ \\
\hline a & $r \circ / \Delta \Delta a$ & $\mid K Y_{0} / 99^{a}$ & $\Delta / r^{a}$ & $\mid k y d / 1$ a & TYYG/A a & TrVb & $\mathrm{T}$ \\
\hline & $r Y / r \Delta^{a}$ & $\mid r M \Lambda / Y^{a}$ & $0 / 19^{a}$ & $1909 / 9^{a}$ & TVO $\left.\right|^{a}$ & $r Q 0^{a}$ & $\mathrm{D}_{1}$ \\
\hline$Y / V^{a}$ & $r / / 90 \mathrm{a}$ & a & $\varphi / q^{a}$ & $1 \Delta \& q / r^{a}$ & $r \Delta Y Y / \Delta^{a}$ & & $\mathrm{D}_{2}$ \\
\hline$r / r \Delta^{b}$ & $\Lambda / T \Delta^{b}$ & $\vee 90 / \mathrm{N}^{\mathrm{b}}$ & $r / \Delta \mu^{a}$ & $1 \circ \circ \Lambda / 4 b$ & $10 \Delta r / /^{b}$ & $r / r / 9 V^{b}$ & $\mathrm{D}_{3}$ \\
\hline
\end{tabular}

آبيارى نشان داد كه اختلاف معنسىدارى بـين ارتفـاع تيمارهـاى

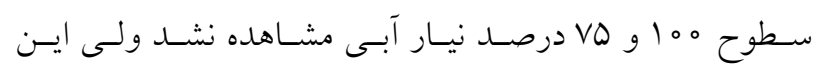

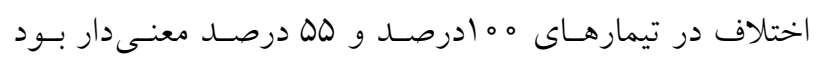
(جدول \&). همجنين مطابق شكل (1)، ارتفاع تيمار T در سـطح

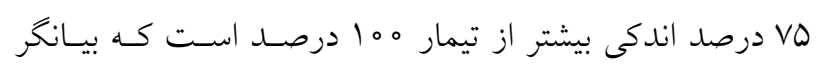

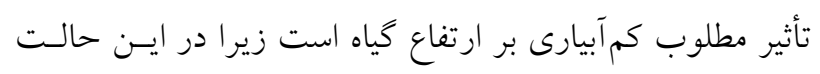

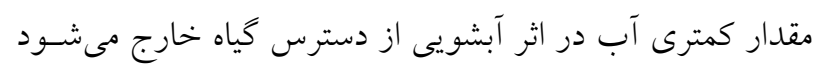
و كياه حداكثر استفاده را از آب موجود مسىكنـد. مطـابق نتسايج بهدست آملده ارتفاع گيـاه در تيمارهـاى مختلـف كـمآبيـارى در

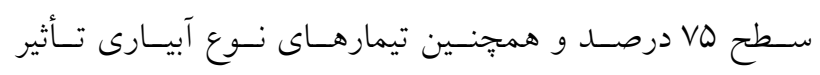

معنى دار نبوده است. همجنين مطابق جدول مقايسه ميـانخينهـا،

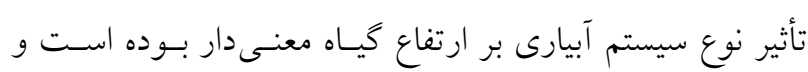
ارتفاع بوته در آبيارى قطرهاى كاهش و 9/19 درصدى نسـبت بـــ آبيارى شيارى داشته است، بهطورى كه بيشترين ارتفاع گيـاه در

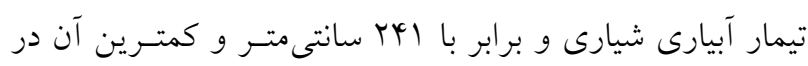

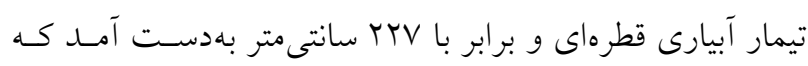

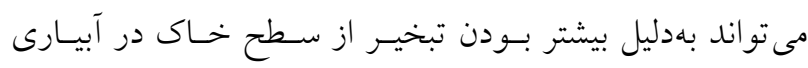

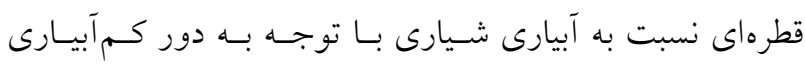
قطرهاى بهخصوص در تيمار آبيـارى هل درصسـ نيـاز آبسى بـود

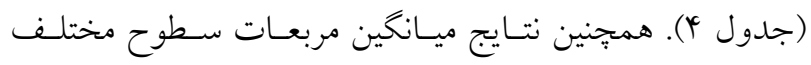




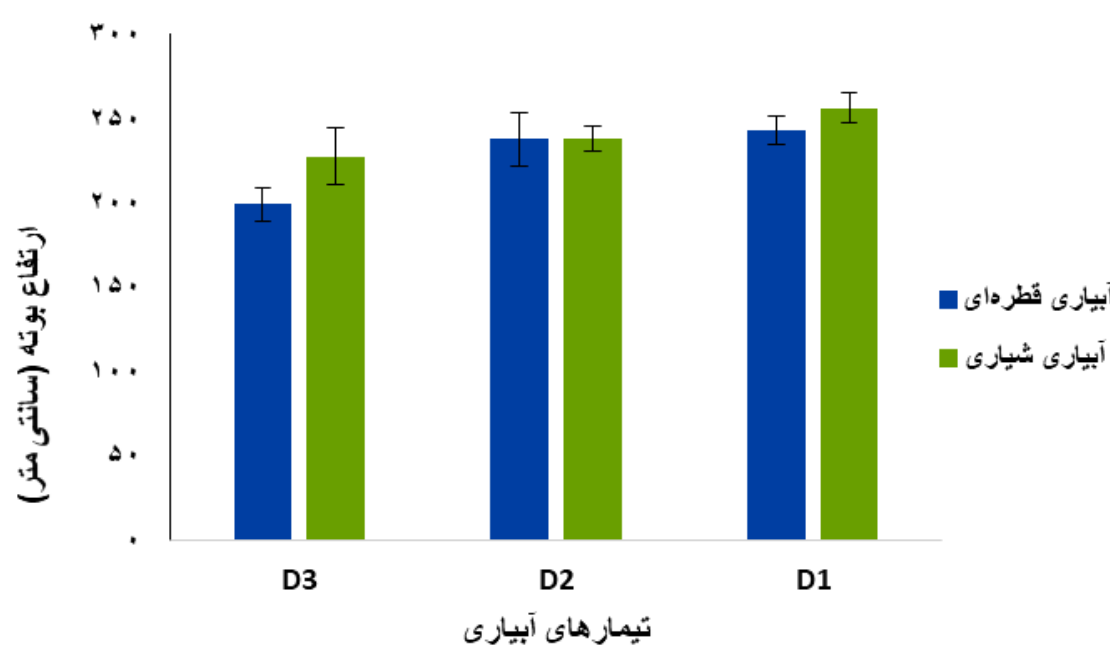

شكل 1. ارتفاع گياه براى تيمارهاى مختلف روش آبيارى و در سه سطح كم آبيارى 0 م

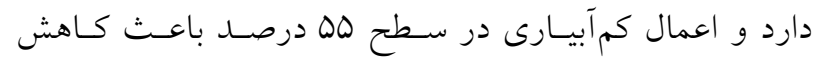
r Fr/Or

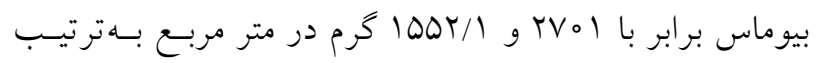

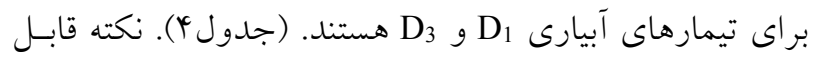

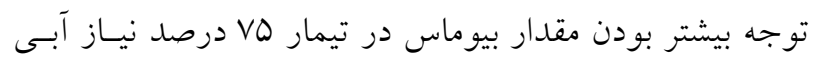

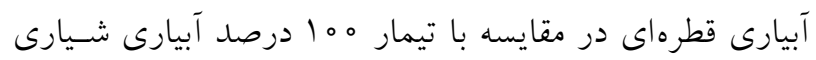

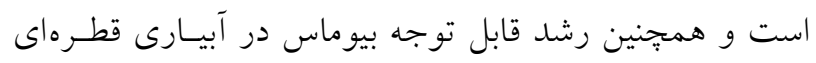

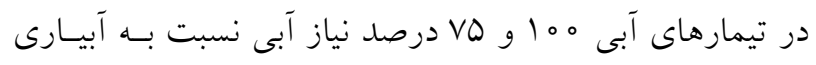

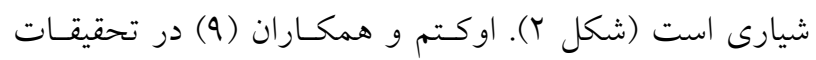

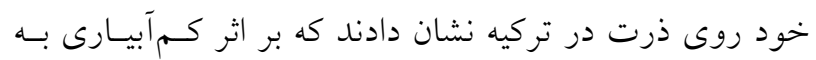

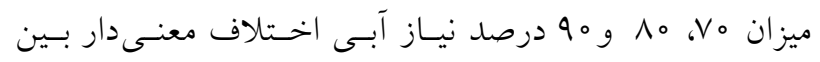
بيوماس تيمارها رخ مىدهد.

وزن بلال نتايج تجزيه واريانس دادههاى وزن بلال نشان داد كه تأثير تيمار

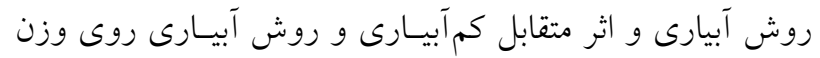

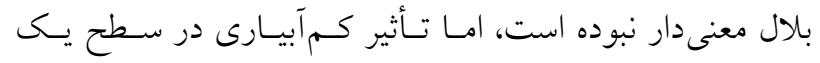

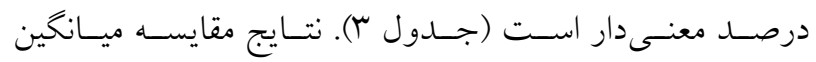

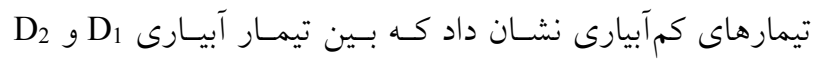

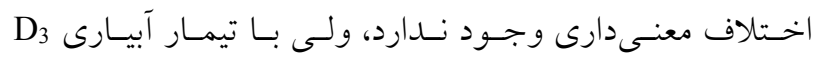

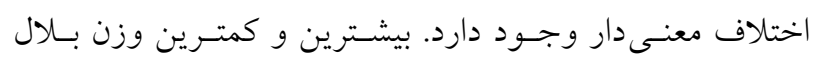

معنسى دارى بــر ارتفـاع نداشـتند. نتـايج تحقيـق انجـام شــده بـا

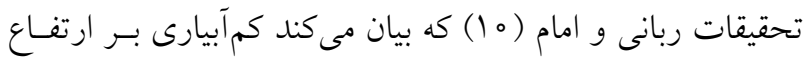

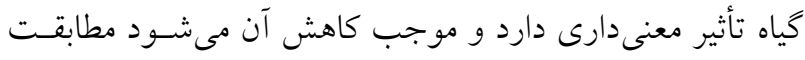
دارد.

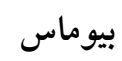

نتايج تجزيه واريانس دادهها نشـان داد كـه تـأثير تيمـار روش آبيارى روى وزن خشك زيست تودهه (به كليه قسمتهاى گيساه

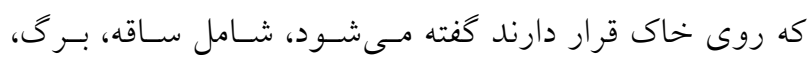

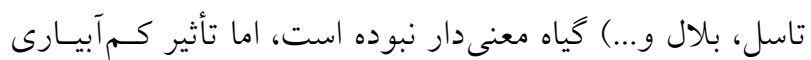

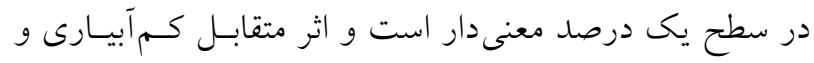

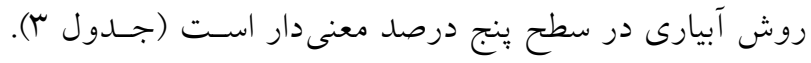

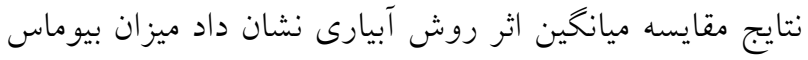

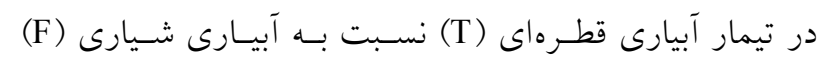

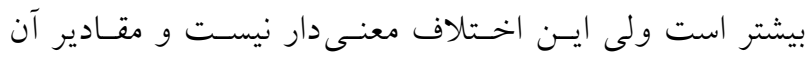

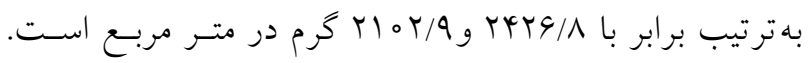

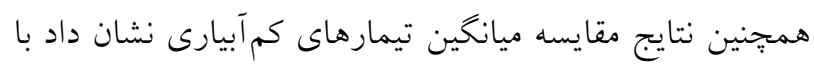

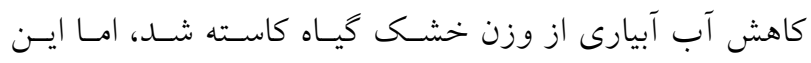

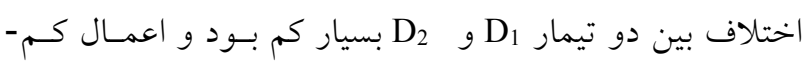

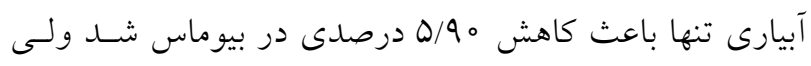

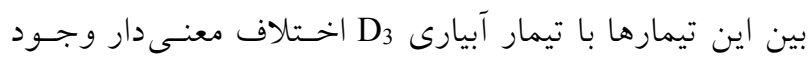




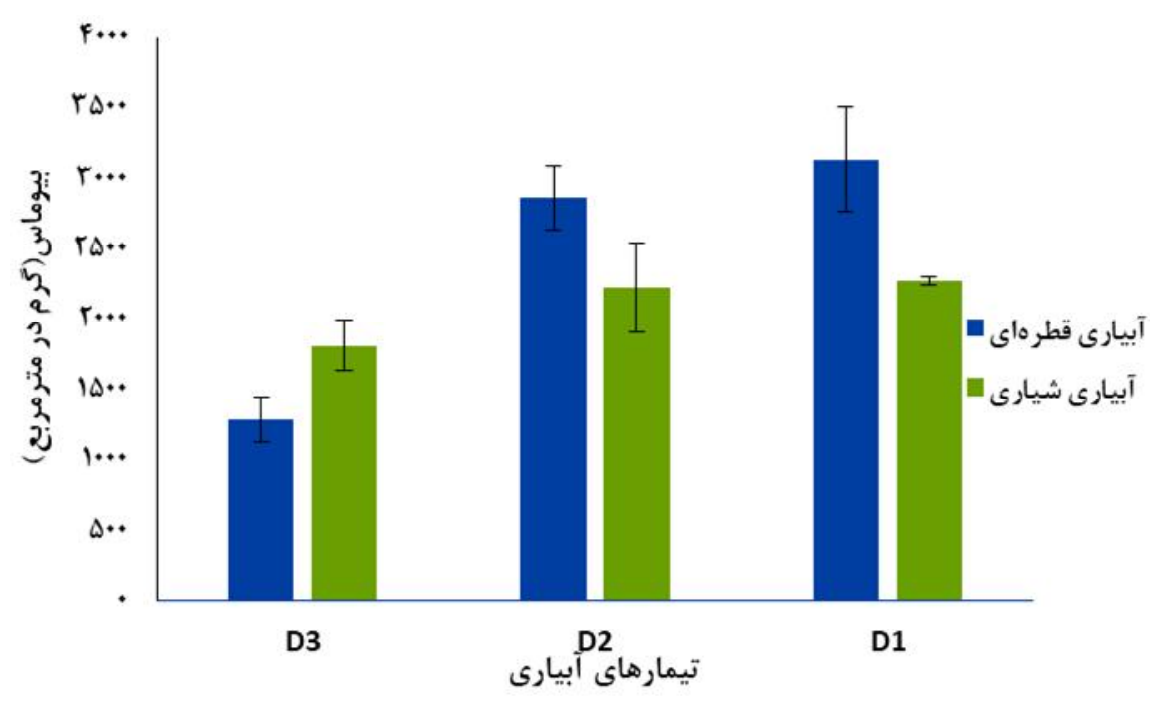

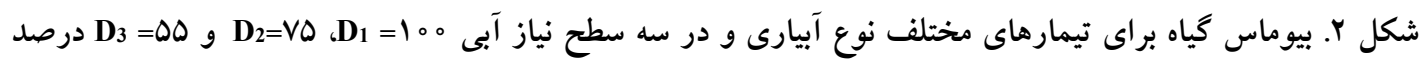

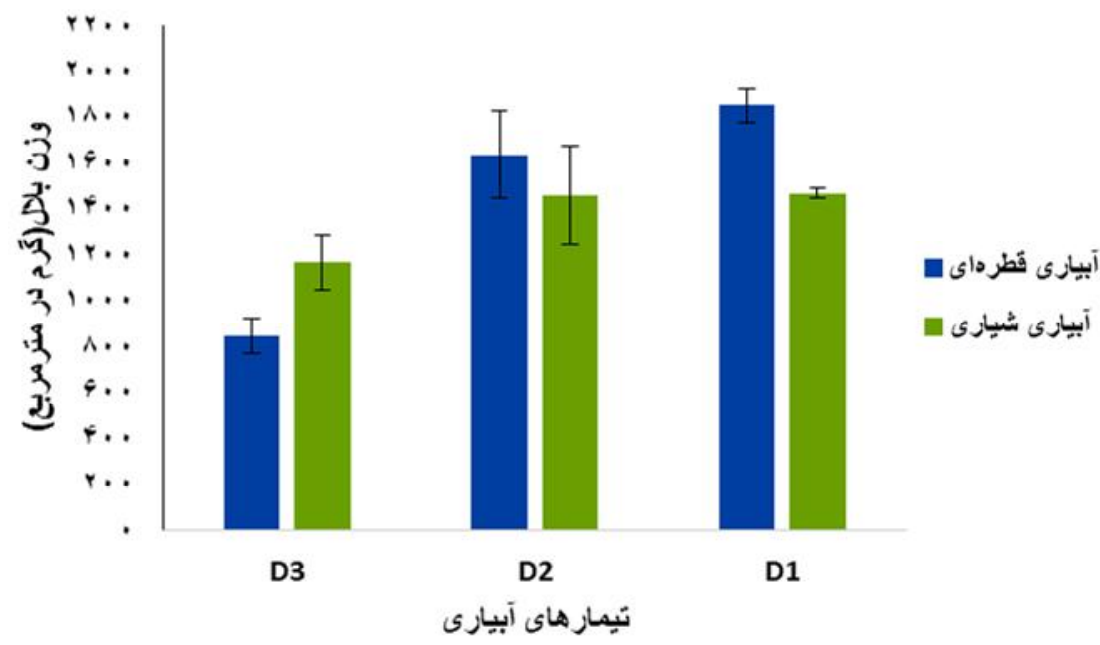

شكل r. وزن بلال گياه براى تيمارهاى مختلف نوع آبيارى و در سه سطح نياز آبى ه

بلال بهترتيب در تيمار VD درصد آبيارى قطرهاى نسبت به 100

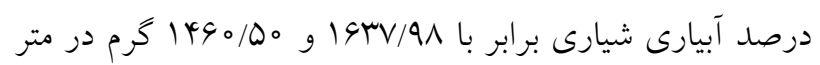

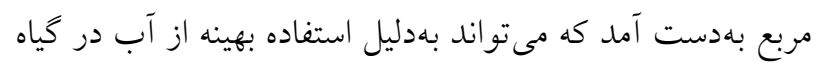

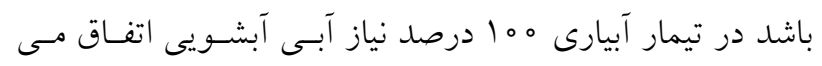

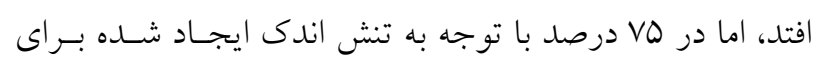
كياه افزايش كيفيت رخ داده است.

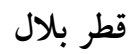
نتايج تجزيه واريانس دادهها نشان داد كه تأثير تيمار كـمـبيـارى بلآ

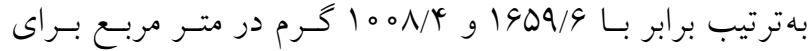

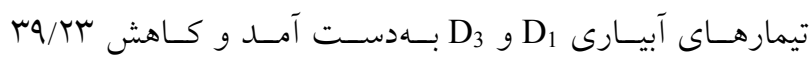

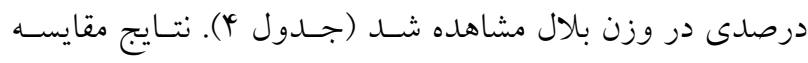

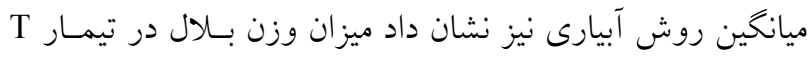

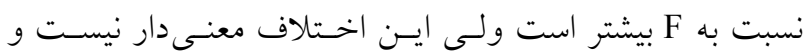

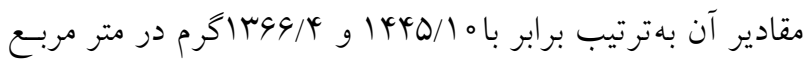

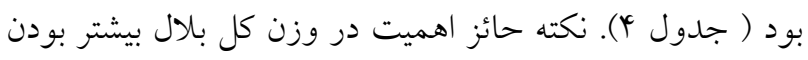

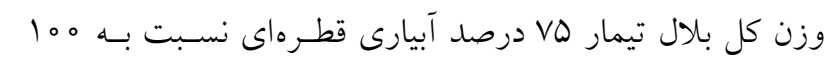

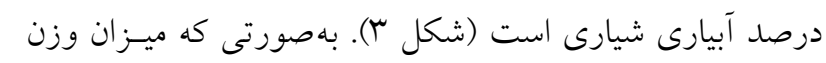




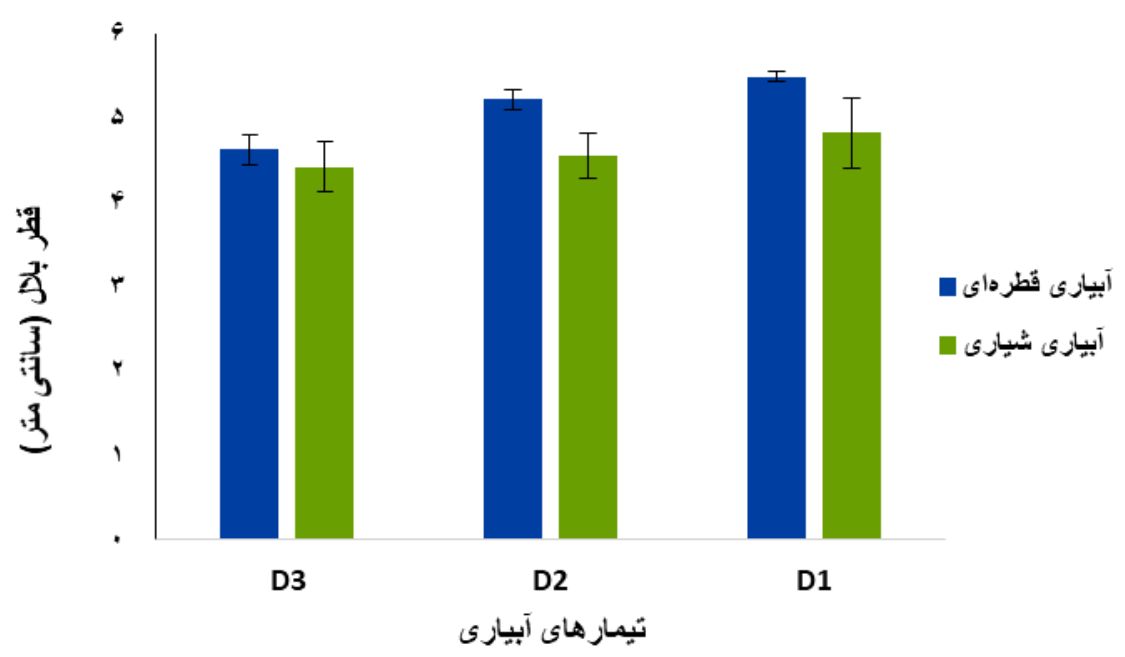

شكل f. قطر بلال گياه براى تيمارهاى مختلف نوع آبيارى و در سه سطح نياز آبى ه م

كم آبيارى در سطح يك درصد معنى دار اسـت و همجنسين اثـر

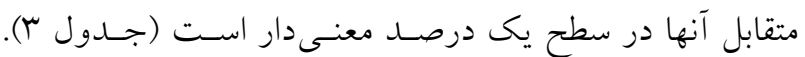

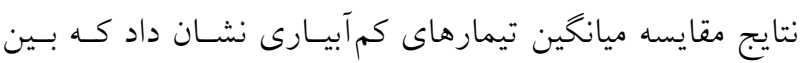

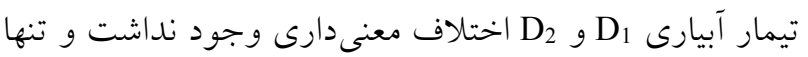

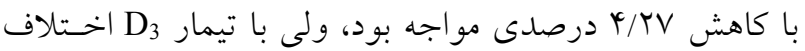
معنى دار 9 ا9 درصدى وجود داشـت. بيشـترين و كمتـرين

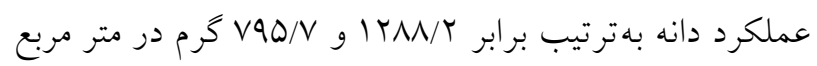

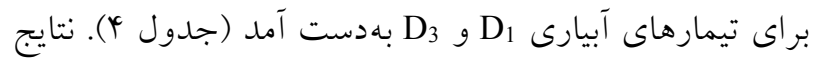

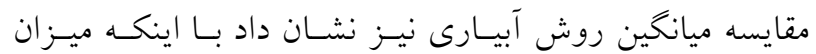
عملكرد دانه در تيمار T نسبت به تيمـار F، در حسدود TV/NI درصد بيشتر بود ولى اين اختلاف معنى دار نبود (جـدول \&). نتايج بهدست آمده نشان داد كه مقدار عملكرد دانسه در تيمـار

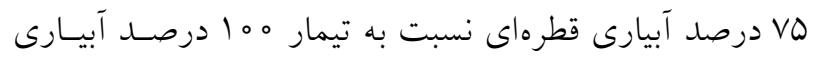
شيارى بيشتر شد و بيان كننده اين است كه مى توان با استفاده

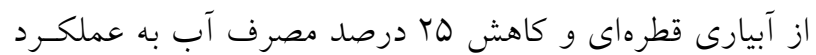

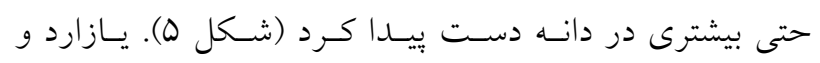

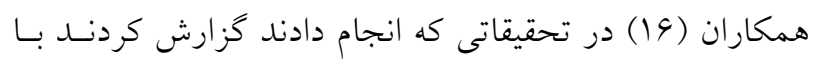

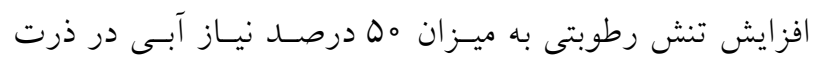

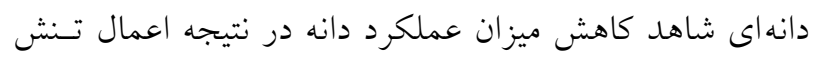

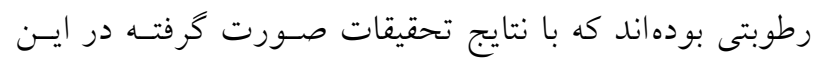
آزمايش منطبق است.
و اثر متقابل كمآبيارى و روش آبيارى روى قطر بـلال معنسى دار

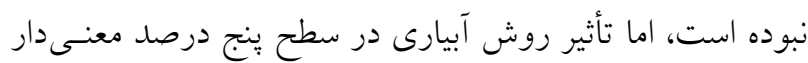

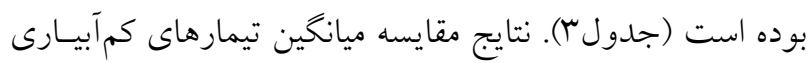

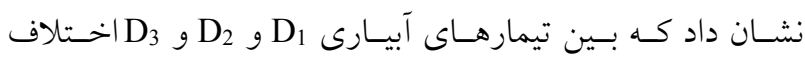
معنى دار وجود دارد. بيشترين و كمترين قطر بلال بهترتيب برابر

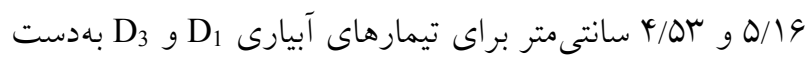

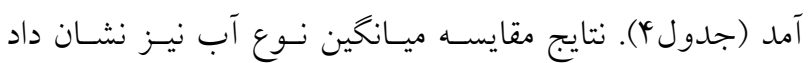

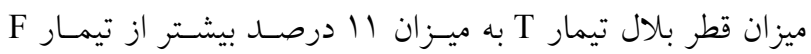
است و اين اختلاف معنى دار است (جدول \&). در شكل (Y) نيز

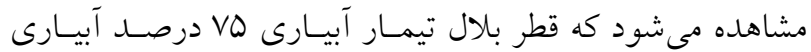

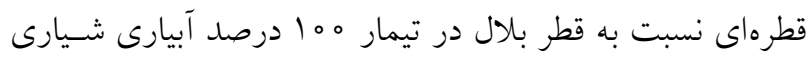

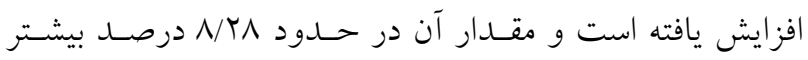

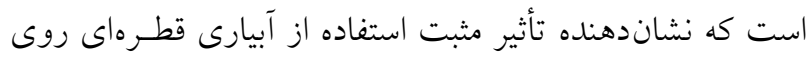

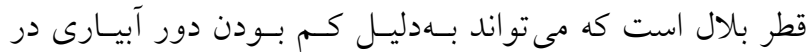

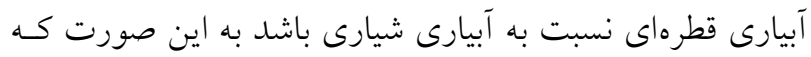

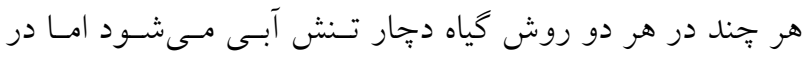
آبيارى قطرهاى گياه همواره مقدارى آب در اختيار دارد.

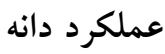
نتايج تجزيه واريانس دادهها نشـان داد كـهـ تـأثير تيمـار روش دانه آبيارى روى عملكـــد دانـهـ معنسى دار نبـوده اسـت، امـا تـأثير 


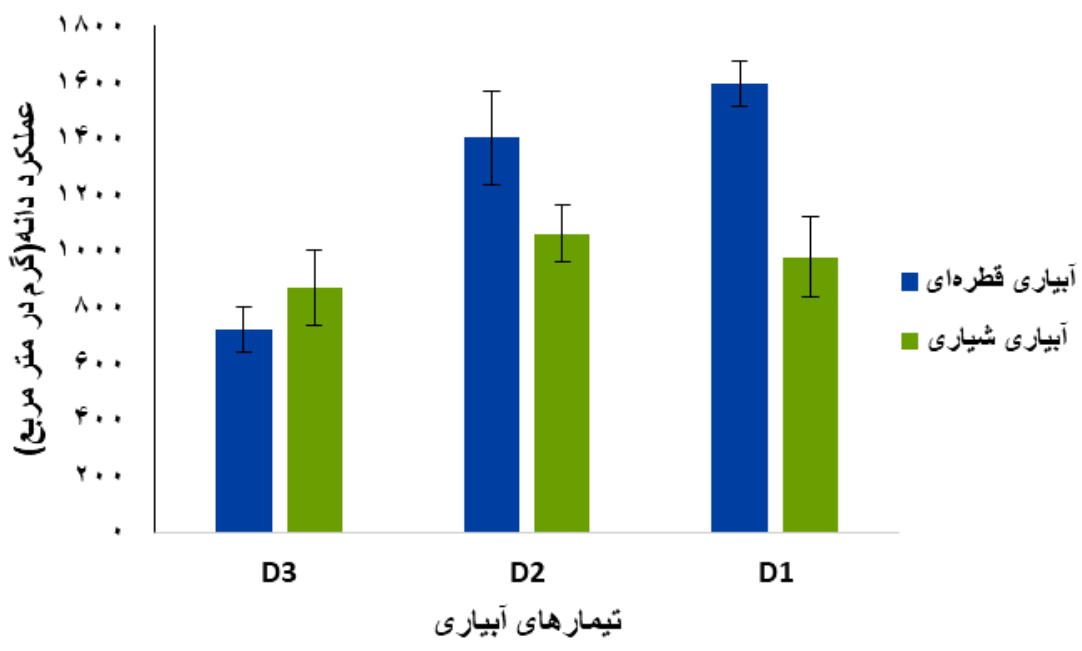

شكل ه. عملكرد دانه گياه براى تيمارهاى مختلف نوع آبيارى و در سه سطح نياز آبى ه ه

بلال مىشود و بــا تحقيقـات صـورت كرفتـه در ايسن يـرزوهش

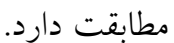
كار آيى مصرف آب

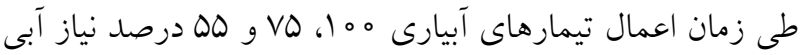
بهترتيب VWV قرار كرفت. نتايج تجزيه واريانس دادهها نشان داد كه تأثير تيمار روش آبيارى بر كارآيى مصرف آب معنسىدار نبـوده اسـت، امـا

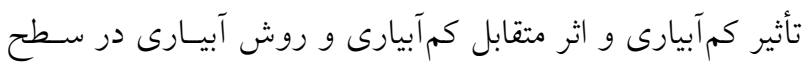

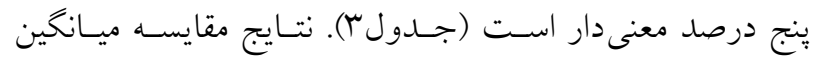
روش آبيارى نيز نشان داد كار آيى مصرف آب در تيمـار F و T،

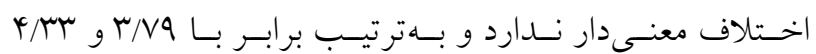

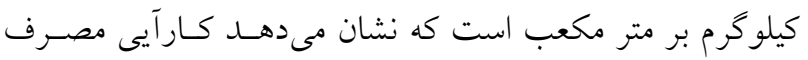

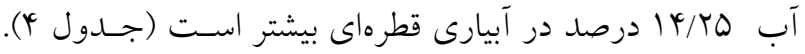
نتايج مقايسه ميانخين تيمارهاى كم آبيارى نشان داد كه بين تيمار

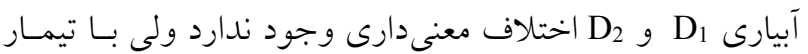
آبيارى D3 اختلاف معنسى دار وجسود دارد. بيشسترين و كمتسرين

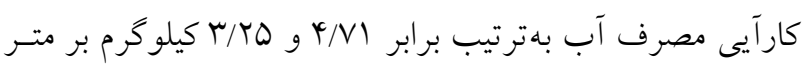

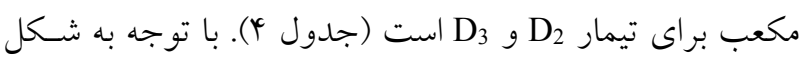

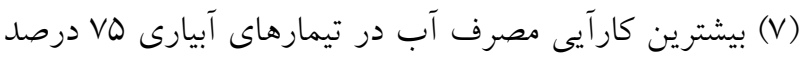

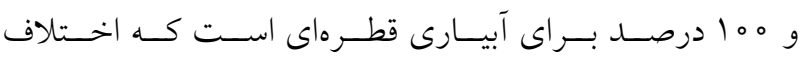

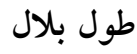

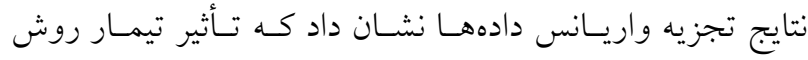

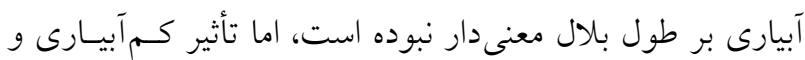

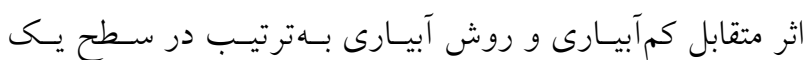
درصد و ينج درصـد معنسى دار بـوده اسـت (جــول ب). نتسايج مقايسه ميانكين نوع آبيارى نيز نشان داد طول بلال در دو تيمـار

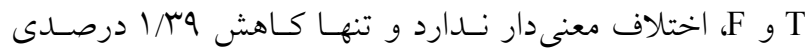

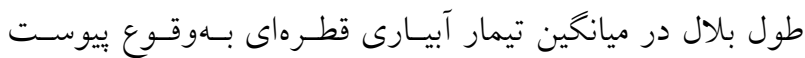

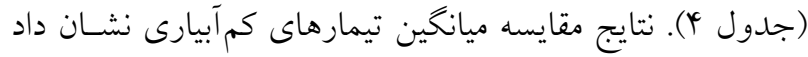

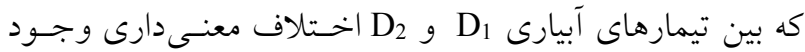
نداشت و تنها با كاهش ب//4 درصدى مواجه شد، ولى با تيمـار اختلاف معنى دار وجود دارد. بيشترين و كمترين طول بـلال

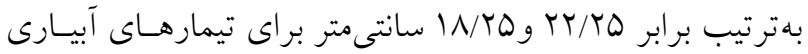

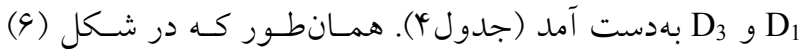
مشاهده مىشود طول بلال در تيمار VD درصد آبيـارى قطرهاى

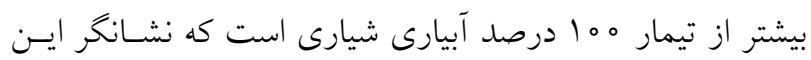

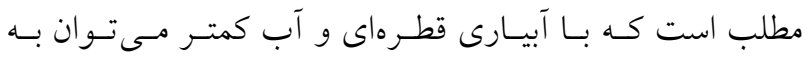
محصـول بيشـتر و بـا كيفيـتــــى دسـت يافـت. سـيدزوار و و

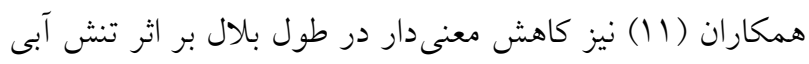

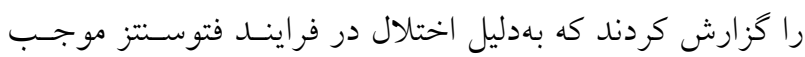

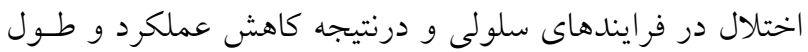




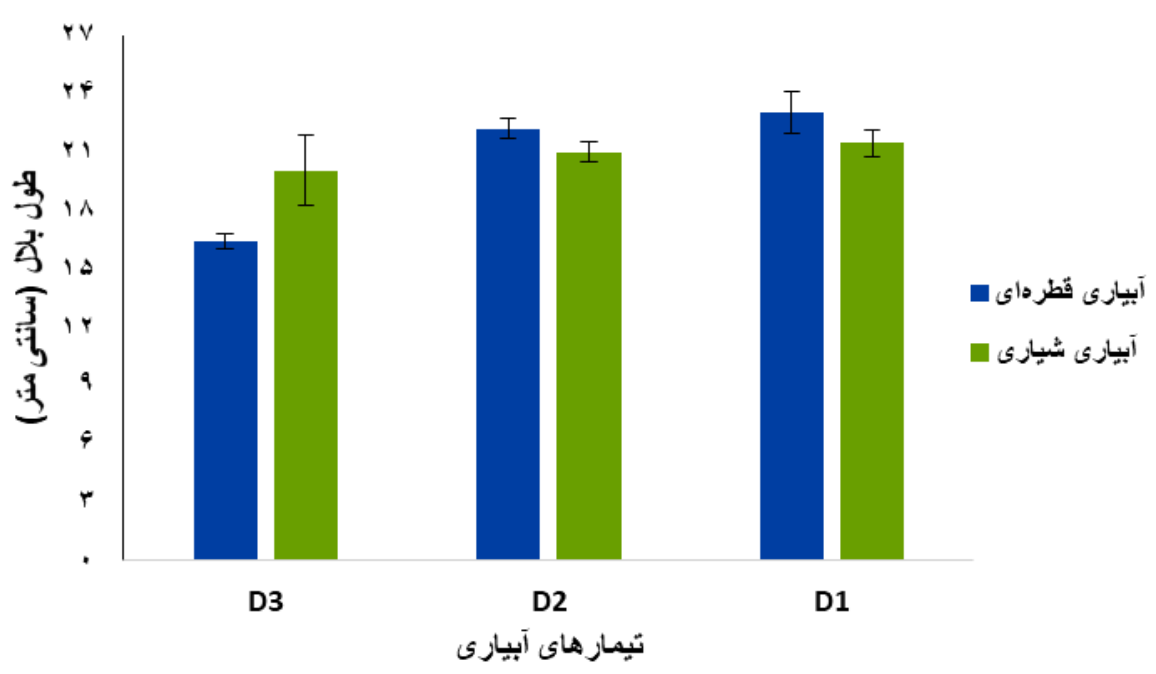

شكل 9. طول بلال كياه براى تيمارهاى مختلف نوع آبيارى و در سه سطح نياز آبى ه

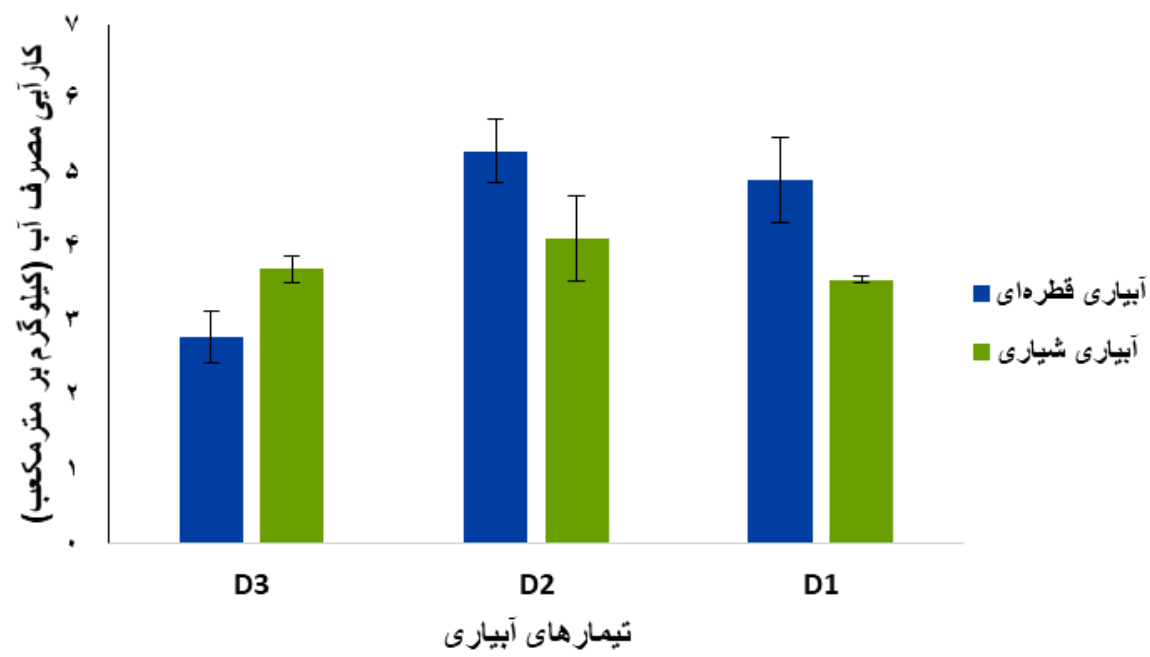

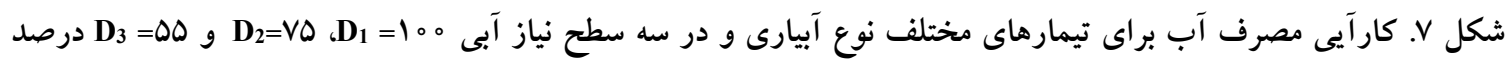

مصرف آب و يافتن مناسبترين تيمارهاى آبيارى است. نتايج

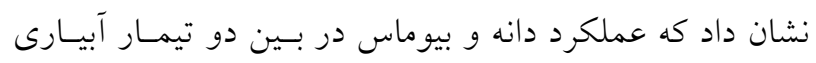

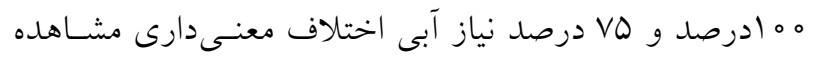

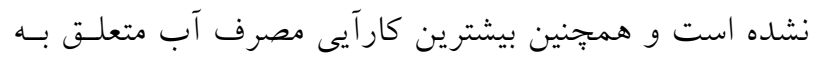

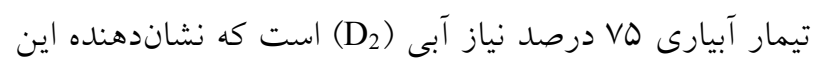

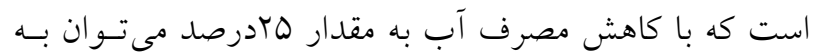

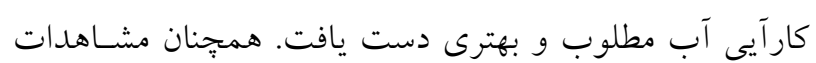

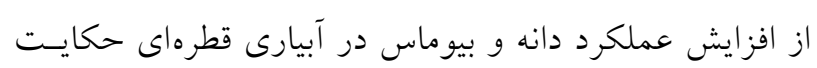

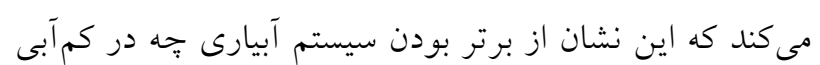

زيادى نيز با آبيارى شيارى دارد اما در هه درصد بــراى آبيـارى

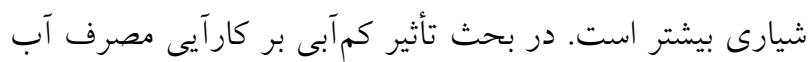

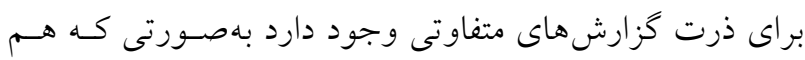

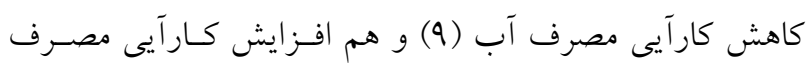

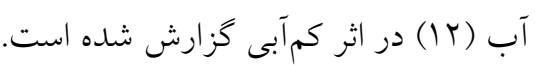

\section{نتيجه گيرى}

هدف از اجراى اين طرح بررسى توأمـان تـأثير كـمـيَآبيـارى و

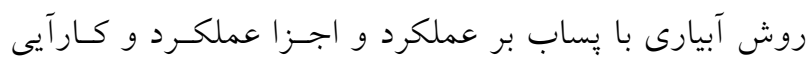




$$
\text { به VD درصد جهه در آبيارى كامل نسبت به آبيارى شـيارى اسـت }
$$

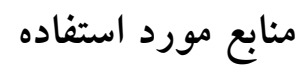

1. Alinejadian, A. and A. Maleki. 2013. Evaluation of water use efficiency and corn function in irrigation with urban wastewater in cold climates. First National Conference on Water and Agriculture Water Challenges. Isfahan, Iranian National Irrigation and Drainage Association.

2. Dehghanisanij, H., M. Zounemat-Kermani and R. Asadi. 2014. Application of municipal wastewater in irrigation of corn under furrow and drip irrigation systems. Iranian Journal of Irrigation and Drainage 8(3): 423-429. (In Farsi)

3. Deng, X. P., L. Shan, H. Zhang and N. C. Turner. 2006. Improving agricultural water use efficiency in arid and semi-arid areas of China. Journal of Agricultural Water Management 80: 23-40.

4. Ghobadi, R., A. Shirkhani and A. Jalilian. 2015. Effects of water stress and nitrogen fertilizer on yield, its components, water and nitrogen use efficiency of corn (Zea mays L.) cv. SC. 704. Agronomy Journal (Pajouhesh \& Sazandegi) 104: 79-87. (In Farsi).

5. Heidary, A., R. Choukan, A. Tashakori and H. Kalantari. 2012. Hybrids (Zea mays L.) effects of different levels of drought stress on yield and yield components of corn. Journal of Water and Soil 25(6): 1250-1263. (In Farsi).

6. Karandish, F., S. M. Mirlotfi, A. Shahnazari, F. Abbassi and M. Ghaesari. 2014. Investigating the effect of defective root irrigation and conventional irrigation on water productivity and yield components and yield components of corn. Iranian Journal of Soil and Water 44(1): 33-44. (In Farsi).

7. Malekian, R., M. Haidarpour, B. Mostafazadeh and G. Abedi. 2008. Effect of surface and subsurface irrigation with refined effluent on grass characteristics. Journal of Agricultural Sciences and Natural Resources 4: 16-27. (In Farsi).

8. Mostafazade, F. B., S. A. M. Mirmohammadi and M. Y. Kupane. 2005. Comparison of characteristics of sunflower, corn and sugar beet under different systems of irrigation with wastewater. Iranian Agricultural Science 36(5): 12151222. (In Farsi).

9. Oktem, A., M. Siesek and G. Oktem. 2003. Deficit irrigation effects on sweet corn (Zea mays sooch arata sturt) with drip irrigation system in a semi arid region. I. water-yield relationship. Agricultural Water Management 61(1): 6374.

10. Rabbani, J. and Y. Emam. 2012. Yield response of maize hybrids to drought stress at different growth stages. Journal of Crop Production and Processing 1(2): 65-78. (In Farsi).

11. Seyedzavar, J., M. Norouzi, S. Aharizad and A. Bandehhagh. 2015. Relationship between yield and yield components of maize hybrids under different irrigation. Journal of Crop Ecophysiology 9 (1): 83-108. (In Farsi).

12. Shiri, M. R. and R. Chukan. 2017. Stability tolerance evaluation of maize hybrids. Crop Breeding 9(21): 89-99.

13. Soleimani, A., P. Najafi and H. R. Laraee. 2006. Effects of using treated municipal wastewater on physiological growth indices in maize. Research in Agricultural Sciences 1(2): 11-24. (In Farsi).

14. Tamoutsidis, E., M. Lazaridou, I. Papadopoulos, T. Spanos, F. Papathanasiou, M. Tomoutsidou, P. Mitlianga and G. Vasiliou. 2009. The effect of treated urban wastewater on soil properties, plant tissue composition and biomass productivity in berseem clover and corn. Journal Food, Agriculture and Environment 7(3-4): 782-786.

15. Tavakoli, M. and M. Tabatabi. 2000. Irrigation with treated wastewater. Workshop on Environmental Aspects of Wastewater Use in Irrigation. 1-26. http://www.irncid.org.

16. Yazar, A., F. Gokcel and M. S. Sezen. 2009. Corn yield response to partial root zone drying and deficit irrigation strategies applied with drip system. Plant, Soil Enviroment 55(11): 494-503. 


\title{
Comparison of the Effect of Furrow and Drip Irrigation with Waste Water Combined with Deficit Irrigation on Yield Indices and Water Use Efficiency of Corn
}

\author{
M. Amerian, S. E. Hashemi Garmdareh* and A. Karami ${ }^{1}$
}

(Received: May 1-2019; Accepted: February 25-2020)

\begin{abstract}
Today, one of the biggest challenges facing the world is the lack of water, especially in the agricultural sector. In this research, we investigated the effects of irrigation method and deficit irrigation with the urban refined effluent on biomass, grain yield, yield components and water use efficiency in single grain crosses 704 maize. This research was carried out in a randomized complete block design with two irrigation systems (furrow irrigation (F) and drip irrigation (T)) and three levels of deficit irrigation treatments of $100\left(\mathrm{D}_{1}\right), 75\left(\mathrm{D}_{2}\right)$ and $55\left(\mathrm{D}_{3}\right)$ percent of water requirements in three replications, in 2017, at the collage of Abourihan Research field, University of Tehran, in Pakdasht County. The results showed that the highest yield of biomass was $2.426 \mathrm{Kg} \mathrm{m}^{-2}$ for full drip irrigation treatments; also, there was no significant difference between $D_{1}$ and $D_{2}$ treatments. The highest grain yield was $1.240 \mathrm{~kg} \mathrm{~m}^{-2}$ for the complete drip irrigation treatment. The highest biomass water use efficiency was obtained for the treatment of $75 \%$ drip irrigation, which was equal to $5.3 \mathrm{~kg}$ per cubic meter of water. Therefore, a drip irrigation system with $75 \%$ water requirement is optimal and could be recommended.
\end{abstract}

Keywords: Unconventional water, Irrigation method, Grain yield, Water use efficiency.

1. Irrigation and Drainage Department, Collage of Aburaihan, University of Tehran.

*: Corresponding author, Email: sehashemi@ut.ac.ir 